\title{
BMJ Open Determining the role and responsibilities of the Australian epilepsy nurse in the management of epilepsy: a study protocol
}

Frances Rapport (D) , ${ }^{1}$ Karen Hutchinson, ${ }^{1}$ Geoffrey K Herkes, ${ }^{2,3}$ Andrew Bleasel, ${ }^{2,4}$ Armin Nikpour, ${ }^{2,5}$ Tayhla Ryder, ${ }^{1}$ Chong Wong, ${ }^{2,4}$ Melissa Bartley, ${ }^{4}$ Carol Ireland, ${ }^{6}$ Honor Coleman, ${ }^{7,8}$ Lisa Todd, ${ }^{6}$ Wendy Groot, ${ }^{9,10}$ Mike Kerr, ${ }^{11}$ Sanjyot Vagholkar, ${ }^{12}$ Graeme Shears, ${ }^{7,9}$ Jeffrey Braithwaite (1) ${ }^{1}$

To cite: Rapport F, Hutchinson K, Herkes GK, et al. Determining the role and responsibilities of the Australian epilepsy nurse in the management of epilepsy: a study protocol. BMJ Open 2021;11:e043553. doi:10.1136/ bmjopen-2020-043553

- Prepublication history for this paper is available online. To view these files, please visit the journal online (http://dx.doi. org/10.1136/bmjopen-2020043553).

Received 10 August 2020 Revised 27 December 2020 Accepted 13 January 2021
Check for updates

(C) Author(s) (or their employer(s)) 2021. Re-use permitted under CC BY-NC. No commercial re-use. See rights and permissions. Published by BMJ.

For numbered affiliations see end of article.

Correspondence to Professor Frances Rapport; frances.rapport@mq.edu.au

\section{ABSTRACT}

Introduction Epilepsy is a common neurological condition affecting between $3 \%$ and $3.5 \%$ of the Australian population at some point in their lifetime. The effective management of chronic and complex conditions such as epilepsy requires person-centred and coordinated care across sectors, from primary to tertiary healthcare. Internationally, epilepsy nurse specialists are frequently identified as playing a vital role in improving the integration of epilepsy care and enhancing patient self-management. This workforce has not been the focus of research in Australia to date.

Methods and analysis This multistage mixed-method study examines the role and responsibilities of epilepsy nurses, particularly in primary and community care settings, across Australia, including through the provision of a nurse helpline service. A nationwide sample of 30 epilepsy nurses will be purposively recruited via advertisements distributed by epilepsy organisations and through word-of-mouth snowball sampling. Two stages (1 and 3) consist of a demographic questionnaire and semistructured interviews (individual or group) with epilepsy nurse participants, with the thematic data analysis from this work informing the areas for focus in stage 3 . Stage 2 comprises of a retrospective descriptive analysis of phone call data from Epilepsy Action Australia's National Epilepsy Line service to identify types of users, their needs and reasons for using the service, and to characterise the range of activities undertaken by the nurse call takers.

Ethics and dissemination Ethics approval for this study was granted by Macquarie University (HREC: 52020668117612). Findings of the study will be published through peer-reviewed journal articles and summary reports to key stakeholders, and disseminated through public forums and academic conference presentations. Study findings will also be communicated to people living with epilepsy and families.

\section{BACKGROUND}

The common neurological condition, epilepsy, affects an estimated 65 million people worldwide. ${ }^{1}$ In Australia, some
Strengths and limitations of this study

- In-depth interviews/focus groups will encourage a detailed, thorough examination of epilepsy nurse (EN) roles and responsibilities in supporting people living with epilepsy.

- Findings from the thematic analysis of the interviews will be interpreted in conjunction with the findings of the National Epilepsy Line data analysis to identify the circumstances that lead to people accessing more individualised EN support.

- The level of detail disclosed will lend itself to the consideration of roles and responsibilities of nurses in other care settings.

- Small-scale, mixed-method investigation has limitations for replicability.

- The role and responsibilities of the EN are from the perspectives of nurses only.

$0.6 \%$ of the population live with epilepsy, and between $3 \%$ and $3.5 \%$ will experience epilepsy at some point in their lifetime, with 14000 new diagnoses each year. ${ }^{2}$ Approximately one-third are diagnosed with refractory epilepsy (also known as drug-resistant epilepsy), where seizures persist and seizure freedom cannot be successfully attained through antiepileptic drugs. ${ }^{3}$ Alongside drug therapy, a range of surgical treatment options are available in Australia and a recent systematic review found an increased possibility of seizure freedom with 'resective brain surgery' (median $62.4 \%$ ) for some people with drugresistant epilepsy. ${ }^{4-6}$ However, in Australia as elsewhere, surgery is critically underused.

\section{Delayed care}

Successful surgery can be life-changing, according to individual accounts, ${ }^{7}$ but delays in surgical intervention and other treatment options are apparent (approximately 17 years 
in Australia; 22 years in the USA). ${ }^{8}$ This can place an excessive burden on people living with epilepsy (PLWE) in terms of mental and physical health and well-being. In addition, disease manifestations often include cognitive and/or psychiatric comorbidities, which are frequently exacerbated by disease misdiagnosis and inappropriate treatments, particularly in community and primary contexts. ${ }^{9}$ Thus, by the time many PLWE arrive at specialist Tertiary Epilepsy Centres (TECs), they can have psychosocial comorbidities limiting the potential benefits of surgery and other treatments. ${ }^{1011}$

Delays in appropriate treatment and seizure management are experienced by people living with all types of epilepsies (including the newly diagnosed and those with complex epilepsy). These delays can impact PLWE and their families, with sustained retention in primary and community care sectors leading to system bottlenecks as people wait for specialist care. ${ }^{39}$ As healthcare resources (eg, staffing) are stretched by growing demand on services, and people staying within primary, community or tertiary care not being moved on through the service (or those arriving in TECs staying too long under specialist care), there are growing concerns about a lack of integrated services.

\section{Research investigation}

Work being undertaken by a group of epilepsy researchers, implementation scientists and clinical specialists in New South Wales, Australia, has led to new knowledge about health service use by PLWE. Our team has examined service delays in care delivery ${ }^{812}$ and through an eightphased research programme (2016-2020; figure 1) collected data about individual experience and service use through epidemiological studies, patient medical record reviews, and studies examining quality of life and patient need using narrative, textual and observational material. The programme has revealed a clear correlation between service delays and physical, mental and psychosocial deterioration, pervasive across adult groups. Service delays can affect decision-making, shared care and patient information provision. ${ }^{9}$ Indecision is also an issue for patients, exacerbated by care fragmentation, ${ }^{9}{ }^{13}$ lengthy waits, ${ }^{114}$ the need to navigate complex systems, ${ }^{19} 12$ lack of patientfocused care,${ }^{9}$ professional misunderstanding,,${ }^{912}$ healthcare professionals' (HCPs) limited access to information ${ }^{9}$ and inadequate resourcing (staff and financing). ${ }^{12}$

\section{Research implications}

The research programme benefitted from patient involvement, while service-user organisations supported access to community services. To date, outcomes have been largely framed by the patient-reported determinants of health and well-being model (the Patient Reported, ImpleMentation sciencE mode ${ }^{13}$ ), offering new evidence around patients' sense of self and physical and emotional well-being. ${ }^{9}{ }^{13}$ Clinical audits and epidemiological assessment of service use and mortality rates ${ }^{814}$ have also

Overview of epilepsy research at Australian Institute of Health Innovation (AIHI)

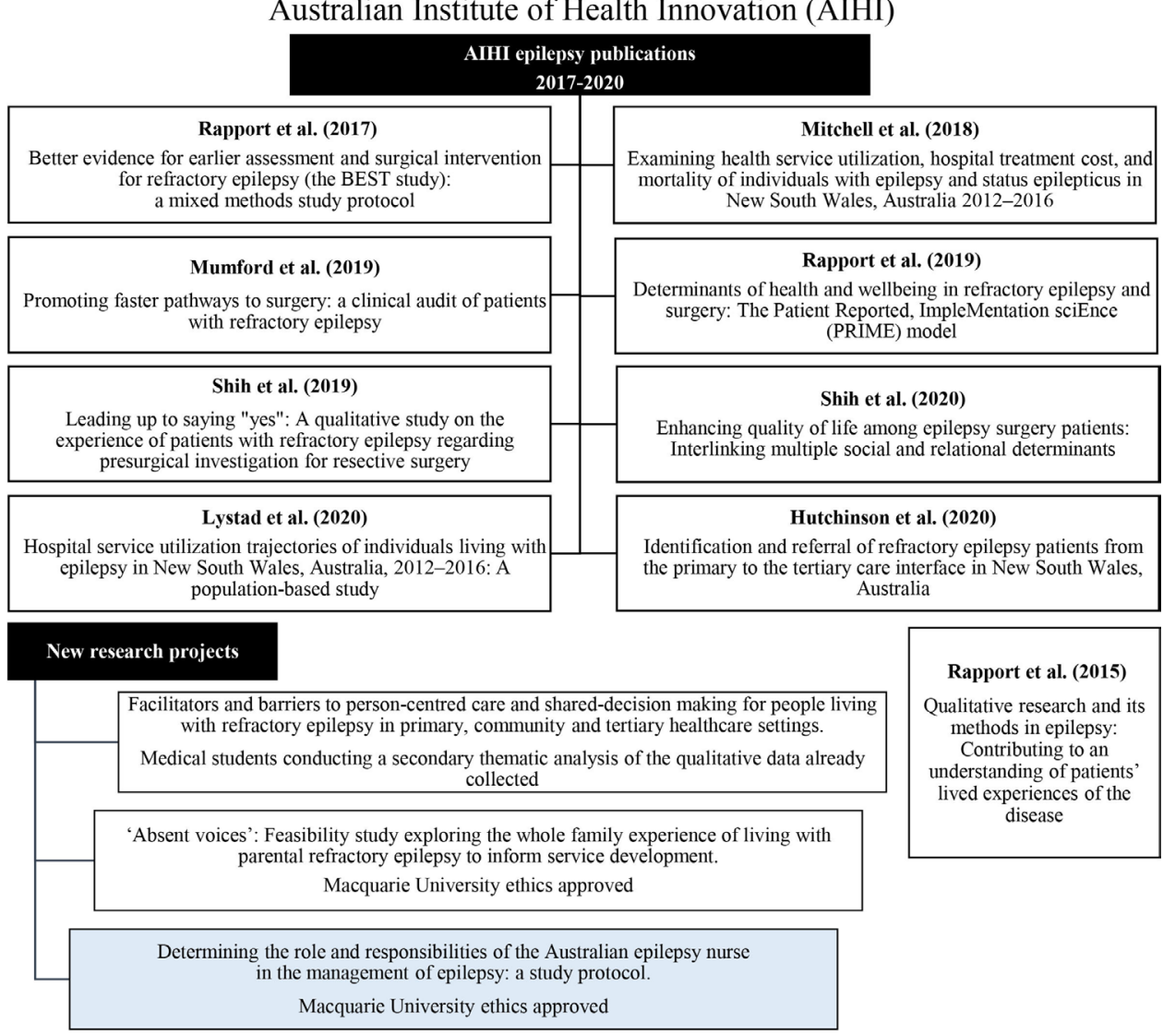

Figure 1 The eight-phased research programme in refractory epilepsy (2016-2020). 
indicated adjustments needed to improve care, alongside evaluations of professional practice at different stages in the patient journey ${ }^{9}$ : information-sharing; patient throughput and professional collaboration. For example, having examined the pressure that system bottlenecks place on TECs, we discovered a range of resource impacts where hospitals reject new referrals (in part, resulting from a lack of clinical space to meet demand). We also noted patients' unwillingness to transition out of TECs back into the community setting, suggesting concerns regarding community practitioners' capacity for patient support. $^{914}$

\section{Epilepsy nurses}

Drawing on foundational concepts in implementation science as the theoretical basis for our work, ${ }^{15}$ we have relied heavily on the views of PLWE, epileptologists, general neurologists, neurosurgeons, primary care practitioners and neuropsychologists to inform our knowledge base. The literature echoes this reliance, indicating a lack of information surrounding family, carer and friends' views and their experiences of care quality.

In addition, the voices of Australian epilepsy nurses (ENs) are lacking in the literature. We know that ENs can interact with people who experience seizure activity at various stages of treatment and care, working across primary, community and tertiary practices, emergency departments, neurology wards, outpatient clinics, private specialist rooms, and the general community in private, government and not-for-profit service organisations. However, we do not know their views of interactions with PLWE, interprofessional care relationships, their sense of responsibility for working with others, their ability to educate and inform to alleviate patient frustration, and create realistic expectations for patients and families.

We also know little of their role in person-centred management (with refractory epilepsy and other types of epilepsy), or of providing advice to PLWE at different stages of diagnosis and care. We also know little of their integrated role in epilepsy care and management planning. This, in spite of a growing recognition of the benefit of nurse investment in improving chronic disease management and mental health in primary care settings. ${ }^{16-18} \mathrm{We}$ recognise, from research undertaken in other countries such as the UK, Ireland, France, Canada and the USA, that ENs may be a pivotal element of integrated care, supporting service access, self-management, advocacy and expert disease knowledge. ${ }^{19-22}$ However, research evidence from elsewhere, including Australia, is lacking or missing. ${ }^{19}$

According to the 2008 Western Australia Epilepsy Services Model of Care, ${ }^{23}$ the EN is a vital player in ensuring patients' smooth transition through the health system. The UK's National Institute of Clinical Excellence (NICE) guidelines indicate that ENs influence access for PLWE, not only to suitable clinical services, but also to other services, including social care and counselling services. ${ }^{24}$ In addition, we know that ENs can join physicians to provide more timely access to advice that is important in the paroxysmal expression of seizure disorders. Their role, in both community and tertiary settings, also helps PLWE and their families interpret and act on test results. The NICE guidelines ${ }^{24}$ aim to ensure that all PLWE are seen between scheduled clinical reviews and supported effectively in the community for improved person-centred outcomes. Moreover, despite the small number of EN specialist nurses in the UK, the NICE guidelines attempt to systematise contact with PLWE, ensuring they are seen at diagnosis and receive ongoing EN review, before and after clinical consultation.

Fitzsimons $e t a l^{21}$ examined evidence-based models of care for PLWE in Ireland, finding the EN role to be one of education: empowerment to self-manage and improvement to the integration of care. Fitzsimons $e t$ al note that the impact of nurse interventions on health outcomes such as seizure frequency, health service use and cost is a subject largely unexplored, with limited opportunities for generalisability across nurse interventions regarding intervention effect. ${ }^{21}$ Nevertheless, Fitzsimons et $a l^{21}$ make a strong case for the pivotal position of the EN in empowering patients and enhancing integration of epilepsy care. In addition, Higgins et $a l^{2225}$ provide evidence of the EN's leading role in the progression of evidence-based care underpinning service delivery across organisations and sectors.

As highlighted in a recent mapping review, the EN role, originally established in the UK, has since evolved in many ways across different locations, including further specialisations in areas such as paediatrics and prescribing. ${ }^{19}$ However, these developments have by no means influenced applications in other parts of the world, with a lack of systematic development of this role worldwide. ${ }^{19}{ }^{20}$ Indeed, many countries do not have ENs. In Australia, while the role does exist, research has yet to investigate its significance as part of community initiatives; as well as role acceptability and differentiation, nurse responsibilities, and frequency of contact with PLWE and families between scheduled clinical reviews. Research in Australia has yet to assess the EN role, the varied groups ENs support and those whose needs are not being met as a result of current models of practice. There is also the need to examine which elements of their role contribute to effective delivery of person-centred care. It is recognised globally that ENs have an important role to play in a multidisciplinary team, in advocacy and advice giving, continuity of care, self-management programmes, educational provision for statutory and voluntary organisations, and sharing of expert knowledge; but more research is required to standardise and develop their roles. ${ }^{19} 2026$

This protocol aims to clarify the EN network within Australia including interprofessional connections, as well as the EN's influence on the well-being and care of PLWE, and EN relationships with families and others as there is little standardised information in Australia about EN roles and qualifications or nationally standardised 


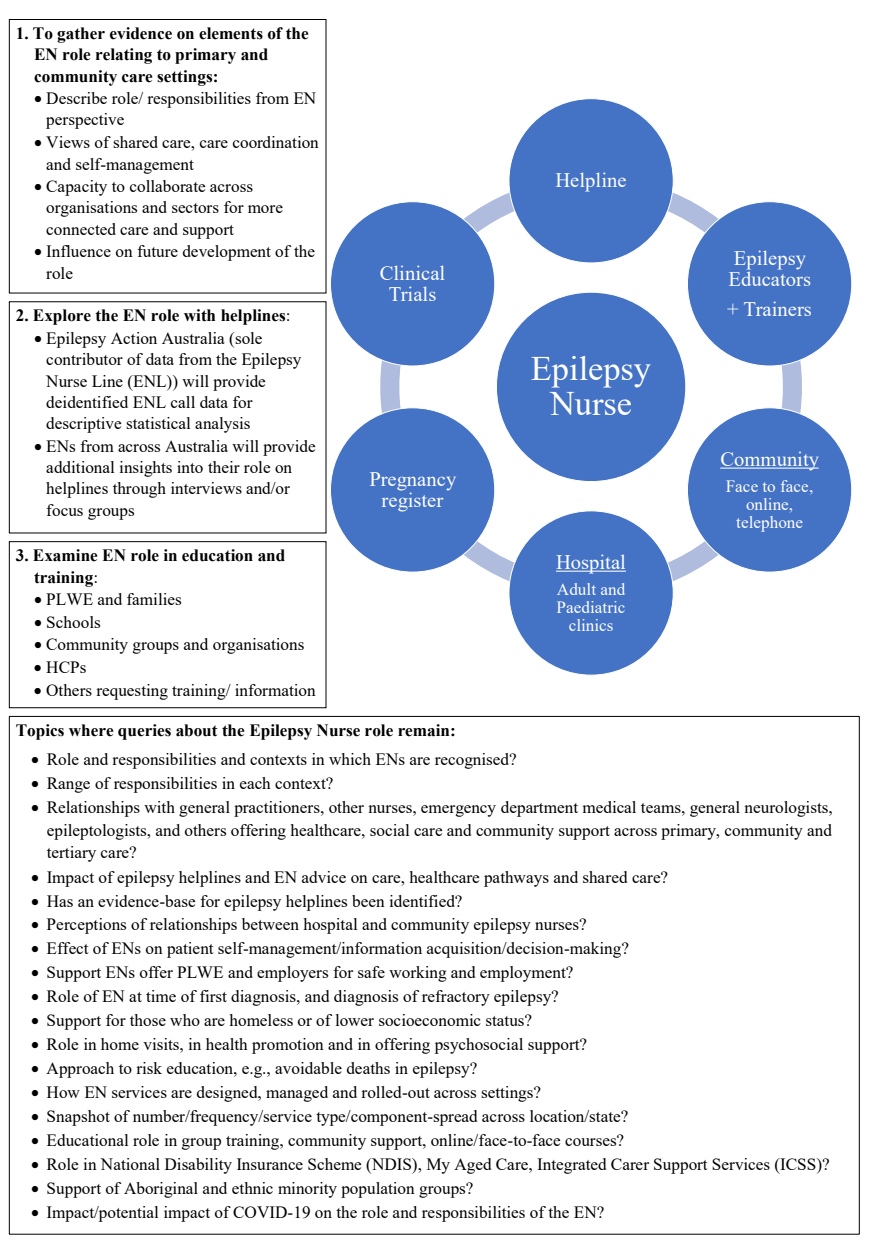

Figure 2 Generating knowledge and understanding of EN arrangements in Australia. EN, epilepsy nurse; HCPs, healthcare professionals; PLWE, people living with epilepsy.

training programmes. It will also provide insights into Australian service delivery. Due to the broad contexts in which ENs and PLWE intersect, we will primarily explore the elements of their roles and responsibilities that apply to working in primary and community settings. Knowledge gained will highlight the capacity for ENs to respond to PLWE, their families, other HCPs and changes in service delivery, particularly relevant under the current COVID-19 public health crisis (see figure 2 for a synthesis of current knowledge of EN arrangements in Australia and unanswered queries).

\section{AIMS}

\section{Primary aim}

Clarify the Australian EN role in supporting PLWE, contributing to future developments of the role and advancing integrated care.

- Assess the role and responsibilities of the EN across Australia for people living with all types of epilepsies in the community, including the newly diagnosed and those with well-controlled epilepsy, but with particular reference to refractory epilepsy.
- Define community EN services including the National Epilepsy Line (NEL) (Epilepsy Action Australia/ EAA), ${ }^{27}$ taking account of characteristics of caller need and call outcomes.

\section{Objectives}

- Clearly articulate the essential elements of the EN role and responsibilities in the Australian context, particularly in primary and community care settings.

- Understand the EN experience of intersections between primary, community and tertiary care while supporting shared care, inter-professional disease management and efficient patient transitions to TECs.

- Identify EN career pathways, qualifications, training and work experience.

- Clarify EN contributions during a public health crisis (eg, COVID-19) to strengthen service responses at times of crisis.

\section{METHODS}

A three-staged, mixed-method study ${ }^{28}$ will involve semistructured interviews (or where preferable, focus groups) with EN participants using interview schedules to generate rich data. Iterative, thematic data analysis will build an understanding of the EN role as new data are collected, ${ }^{29}$ enhanced by a retrospective descriptive statistical analysis ${ }^{30}$ of de-identified phone calls from the EAA NEL, (the only helpline in Australia to employ solely ENs). ${ }^{27}$ Together, datasets will provide evidence of the significance of the EN role, with a focus on community and primary care. Researcher fieldnotes will accompany qualitative data capture, clarifying dynamic participant interactions. Data will illuminate EN roles and responsibilities, workloads and relationships with community stakeholders (clinical and non-clinical, for example, statutory bodies, members and voluntary organisations). Participant demographic data will clarify the EN's place of work, work characteristics, gender, years of experience in nursing overall and in epilepsy, qualifications, role, role title, employer, age and so on. EAA will provide de-identified NEL data for analysis.

\section{Patient and public involvement}

The involvement of PLWE in earlier studies conducted by the research team informed the development and design of this study.

\section{Sample, recruitment and ethical considerations of participant retention}

An estimated 60 mixed-method data-capture events will take place alongside data from the NEL call log. Thirty EN participants will be involved nationwide:

- Stage 1: 20 interview transcripts.

- Stage 2: call data from the EAA NEL.

- Stage 3: 10 interview transcripts (or 2 focus group transcripts).

- Stages 1 and 2: 30 demographic questionnaires.

- Stages 1 and 3: fieldnotes. 
Participants will be recruited purposively to ensure data collection from ENs working across: (1) metropolitan, (2) inner regional and (3) outer regional/rural/remote locations, with a mix of nurses who support a wide PLWE demographic. Work locations will be defined by the Australian Statistical Geographical Standard Remoteness Area and Statistical Area Level 2. ${ }^{31}$ A purposive participant sample will enable the representation of different participant perspectives while identifying any geographically sensitive issues affecting care and services. Inclusion: all participants currently in an EN role working within Australia. Exclusion: ENs involved in clinical trials or working outside primary and/or community care settings.

EN participants will be recruited nationwide, with support from team members. Recruitment will take advantage of current partnerships with EAA, Epilepsy Australia (EA) and EA partners: Epilepsy Australian Capital Territory; Epilepsy Foundation (EF); Epilepsy Queensland; Epilepsy Tasmania; Epilepsy Western Australia; and the Epilepsy South Australia and Northern Territory. Advertisements will be distributed via social media channels, local and national nurse professional organisations, and through newsletters and flyers. The recruitment strategy will also involve snowball sampling, where recruited participants are encouraged to invite colleagues to contact the research team to participate. This combination of recruitment channels will encourage a comprehensive data collection. Potential participants will be provided with a Participant Information and Consent Form (PICF) with data management and handling requirements, retention of confidential data, data collection and analysis. Study reporting processes will be included, and potential participants will be given the opportunity to ask questions. A 2-week consent turnaround will allow people to consider their involvement. Following a signed returned consent form, recruitment will commence. All participants will be fully informed of their rights, including the option to withdraw from the study at any time without reason, the ethical implications of participation and study plans for data dissemination.

\section{Data collection}

Following ethical approval and participant consent, 4 months of data collection will take place in three stages (see below; table 1).

Stage 1: 20 semistructured telephone, face-to-face or videoconference interviews with ENs across Australia and completion of a demographic questionnaire

Two pilot interviews will pretest the interview schedule (which was derived from a search of the literature ${ }^{192022}$ ) and feedback from pilot data will be used to tailor the final interview schedule. A demographic questionnaire alongside the interviews will collect details of ENs' work location, role, training and training needs, models of service delivery, responsibilities, gender, age range, scope of work and current practices and working arrangements, education and setting. A 1-hour interview with each of the 20 participants will allow for a detailed conversation with a dedicated study researcher. Interviews will be audio recorded, de-identified and transcribed. Fieldnotes will be taken describing interview dynamics and collated in a researcher diary.

Interviews will cover the following topics:

EN career pathway, role/responsibilities in community and primary care contexts (particularly for people with refractory epilepsy, by no means exclusively limited to this group of patients as ENs in this setting also deal with new diagnosis cases and those with less chronic seizure disorders), experiences during COVID-19 pandemic, interactions and relationships with PLWE and families, interprofessional dynamics, information-sharing, family involvement, opportunities for shared decision-making, educational roles, involvement in epilepsy helplines, advocacy, who is accessing EN services and why, what ENs hope to achieve from consultations, service regularity and scrutiny, and liaison across healthcare professional groups. Schedules will concentrate on how nurses respond to the needs of PLWE (whom they meet face-toface, through the NEL or other communication avenues), how information is shared about the needs of PLWE with other HCPs, and whether the epilepsy nurse plays a strategic role in shared care. Consequently schedules do not include topics such as audit or prescribing.

Schedule prompts will allow nurses to diversify from set questions if desired, and ENs may also discuss social care including services provided under National Disability Insurance Scheme, My Aged Care, and Integrated Carer Support Service, educational events and group activities, policy guidance, research activities and the evidence base for roles.

\section{Data analysis}

Qualitative data (interview transcripts/focus group transcripts/researcher fieldnotes) will be analysed thematically in accordance with study aims and objectives. ${ }^{29} \mathrm{An}$ inductive thematic analysis approach will involve the verbatim transcription of all data to identify themes and their concomitant categories. Following a period of familiarisation with the data, an inductive thematic analysis will be undertaken by three analysts working first individually and then together (a primary analyst $(\mathrm{KH})$ and two secondary analysts (TR and RN)). They will consider responses to questions, patterns of speech, and irregularities or issues that appear important or contrary. Inductive thematic analysis is undertaken in a staged manner to ensure a thorough understanding of data as they arrive. Once individual readings have taken place, primary and secondary coders will use $\mathrm{NVivo}^{32}$ to develop a coding framework. Teamwork will allow analysts to review codes to refine the thematic framework. The technique has been extensively applied in other published team studies ${ }^{9}$ adding to the veracity and rigour of the technique. ${ }^{33}$ Data will be inductively coded until saturation is achieved as a means of identifying meaningful units of text. ${ }^{29}$ Qualitative findings will be triangulated with EN questionnaire 
Table 1 Study outline: stages $1-3$

\begin{tabular}{lll}
\hline $\begin{array}{l}\text { Stage 1 } \\
\begin{array}{l}\text { Australia-wide semistructured } \\
\text { interviews }\end{array}\end{array}$ & $\begin{array}{l}\text { Participants } \\
\text { Demographic questionnaire }\end{array}$ & $\begin{array}{l}\text { Process } \\
\text { Advertising through EAA, EF, EA and EA partner organisations, social } \\
\text { media, snowballing, word of mouth, nurse-specific organisations, etc. }\end{array}$ \\
& Inclusion: ENs working in Australia. & $\begin{array}{l}\text { PICF and demographic questionnaire provided and completed by all } \\
\text { participants before interview. }\end{array}$
\end{tabular}

\begin{tabular}{|c|c|c|}
\hline & $\begin{array}{l}\text { Exclusion: ENs involved in clinical } \\
\text { trials only or working outside primary } \\
\text { and/or community care settings. }\end{array}$ & $\begin{array}{l}\text { Interviews (approximately } 60 \text {-minute duration) conducted face-to-face } \\
\text { (workplace, clinic or venue agreed by participant and researcher), } \\
\text { over the telephone or via video-conferencing. Interviews will be audio } \\
\text { recorded, de-identified and transcribed. Fieldnotes will be taken } \\
\text { (dynamics of interactions) and collated in a research diary. }\end{array}$ \\
\hline & Australia-wide cohort. & A thematic analysis ${ }^{29}$ will be conducted on all qualitative data. \\
\hline Stage 2 & Data & Process \\
\hline
\end{tabular}

Retrospective examination of call De-identified descriptive data will be Letter providing consent from EAA for main university site to access logs from EAA's NEL obtained from NEL calls logged from and analyse de-identified data. 1 June 2019 to commencement of the study.

Where appropriate, confounding
factors will be adjusted in the
analysis. Where adjustment is not
possible, sensitivity analyses will be
performed.

\section{Stage 3}

Australia-wide semistructured interviews (embellish data from stages 1 and 2)

Demographic questionnaire (unless already completed in stage 1)

\section{Participants}

10 data collection events (videoconferencing or face-to-face interviews) and/or up to two focus groups (depending on results from previous stages.

This may include a mix of participants who have agreed to be reinterviewed from stage 1 and new participants.

Inclusion: ENs working in Australia.

Exclusion: ENs involved in clinical trials only, or not working in primary or community care settings.

Australia-wide cohort.
Conduct descriptive statistical analysis using software (such as SPSS or SAS). ${ }^{30}$ Cluster analysis will identify distinct groups of NEL users and correspondence analysis to describe relationship among variables (eg, caller needs, characteristics, call outcomes).

\section{Process}

Advertising through EAA, EF, EA and EA partner organisations, social media, snowballing, word of mouth, nurse-specific organisations, etc.

PICF and demographic questionnaire form provided and completed by all participants before interviews (unless already completed in stage 1).

Interviews or focus groups conducted face-to-face (workplace, clinic or venue agreed by participant and researcher), or via videoconferencing. Interviews/ focus groups will be audio recorded, transcribed and de-identified. Fieldnotes taken by researcher collated in a research diary.

Thematic analysis ${ }^{29}$ of the interview and/or focus group data and researcher fieldnotes.

EA, Epilepsy Australia; EAA, Epilepsy Action Australia; EF, Epilepsy Foundation; ENs, epilepsy nurses; NEL, National Epilepsy Line; PICF, Participant Information and Consent Form.

information for the purpose of corroboration, and with the results of the NEL data analysis for elaboration and expansion. $^{28}$

Stage 2: examination of call logs (to understand what the nurse does and how this shapes their overall role): EAA's NEL

A retrospective study of phone calls made to the EAA NEL service from 1 June 2019 to date of commencement of study will take place. The NEL is a phone and email service available daily, 09:00-17:00, to individuals nationwide. The service is overseen by EAA and aims to improve health outcomes and support PLWE and families. ${ }^{27}$ It is an important part of nurse-led activity. Information is collected about each phone call, reason for the call (eg, daily living, seizure history and management, medical/ health, emotional/social, recreation/leisure, employment and other) and any additional topics (that may include reasons for the call, basic epilepsy information and actions by call taker). EAA will provide de-identified data for descriptive statistical analysis.

Stage 2 will also enable the team to describe the characteristics of caller needs, call outcomes and any impact of the COVID-19 pandemic on call type and frequency. This will be achieved through three aims:

- Identify and describe the reason for the call.

- Characterise the actions taken by call taker, for example, referring callers to an EN for follow-up and 
the breadth of information directly provided to callers (eg, seizure management, employment, medication).

- Identify any changes in types and frequency of calls since a state of emergency was announced on 16 March 2020 by the Australian government (pandemic related).

Identifying the differences between callers who are referred to an EN for follow-up and those who are not will aid interpretation of the interviews and expand on the qualitative findings by uncovering where (ie, for who and for what needs) the support of ENs may be in greater demand.

Stage 3: 10 follow-up interviews (or 2 focus groups) (10 data collection events in total) and the completion of a demographic questionnaire

Stage 3 is intended to ensure the thematic accuracy of the data analysed to date. During stage 3, involvement of a national cohort of $10 \mathrm{EN}$ participants will enable us to delve deeper into and embellish themes generated during stages 1 and 2. Face-to-face, telephone or online interviews (or two online focus groups) will be conducted (depending on findings from the earlier stages). As in earlier stages, interviews will be audio recorded, de-identified and transcribed. Fieldnotes will be taken, and all qualitative data analysed thematically. Stage 3 will provide additional knowledge and understanding of the approaches adopted to support PLWE (including those with refractory epilepsy), and adherence to policy guidelines. Stage 3 will provide the opportunity to explore the potential for EN role development towards a more streamlined model of care. EAA, EF, EA and EA partner organisations and snowball sampling with stage 1 participants will support recruitment. Similar ethical considerations and consent requirements will apply.

\section{Participant recruitment and ethical considerations}

Before data collection, participants in the interviews (and if appropriate, focus groups) will be asked to read and sign a PICF, retain a copy and return the original to the study team. A dedicated study researcher oversees data collection and analysis activities, ensuring due consideration is given to safeguarding participants against risk, harm and discomfort. The researcher will be appropriately supported by a research team with expertise in refractory epilepsy research, implementation science and clinical practice. With regard to stage 2, EAA own the data relating to the NEL and will provide the research team with de-identified data which protect the anonymity of NEL users.

Epilepsy organisations nationwide fully support the study, and international clinical input will aid data interpretation and reporting on a global scale. Community links with nurse contacts and epilepsy organisations will aid recruitment and promote the research through networks and newsletter, while expert advice on the role of ENs nationwide will support knowledge translation and effectiveness, promoting research findings through networks and newsletters.

All materials will be de-identified, with pseudonyms used for participants involved in data reporting. Workplace settings and services will also be anonymised for de-identification purposes, including any data containing verbatim quotations.

The dedicated study researcher will oversee all data collection, analysis, collation, storage and retention while being supported to advance the study write-up and dissemination. Data will be held at the lead university site. Electronic data will be stored in password-protected computers with de-identified data blinded for peer review and accessible only to core team members and the dedicated study researcher.

\section{ETHICS AND DISSEMINATION}

Ethics approval for this study was granted by Macquarie University (HREC: 52020668117612). Findings of the study will be published through peer-reviewed journal articles and summary reports to key stakeholders, and disseminated through public forums and academic conference presentations. Study findings will also be communicated to PLWE and families.

\section{Impact}

Improvements to health and social care services for PLWE and their families are envisaged, including:

1. Improved understanding of EN services, EN qualifications and training, and the provision of services in primary and community settings.

2. Enhanced knowledge of nurse management strategies for PLWE and through use of the NEL.

3. Comprehension of EN responsibilities during a public health crisis: identifying potential opportunities for changing and sharing roles during a crisis.

4. Clarity over untapped resources.

5. Greater understanding of the types of work demands on the EN and community services, and the degree to which nurses interact with other HCPs across health and social care (eg, EAA, EA).

6. Relationships among organisations nationwide and between researchers and advocacy groups.

Wide dissemination and study reporting (publications, presentations at national conferences and an executive summary) will identify how data enhance current knowledge and understanding of nurse roles and responsibilities, PLWE journeys through care and interprofessional relations. In addition, study reports will be shared with academic, professional and other stakeholder audiences (eg, community epilepsy organisations) to highlight what has been learnt about epilepsy management in the Australian community setting and perceptions of responsibilities.

\section{Implications}

The effective management of all epilepsies, with particular reference to drug-resistant epilepsy but not 
exclusively limited to this, can be influenced by a lack of integrated care across primary, community and tertiary contexts. EN professionals are perceived to play a critical role in linkage and liaison with PLWE, families, social care support services, primary and community HCPs, educators and specialist epilepsy professionals, but this has not been investigated in Australia to date, with little research elsewhere. Establishing better shared care pathways and integrated models of care will ensure more informed and involved PLWE with the potential for a reduction in referral delays, and more effective, safe transitions through health and social care systems. The opportunity to explore the EN role before, during and immediately following the COVID-19 public health crisis offers an additional and unique opportunity to develop new collaborations and demonstrate the significance of the EN role at a time of unprecedented challenge to health and social care sectors.

\section{Author affiliations}

${ }^{1}$ Australian Institute of Health Innovation, Macquarie University, North Ryde, New South Wales, Australia

${ }^{2}$ Sydney Medical School, University of Sydney, Sydney, New South Wales, Australia ${ }^{3}$ Neurology, Royal North Shore Hospital, Sydney, New South Wales, Australia ${ }^{4}$ Department of Neurology, Westmead Hospital, Westmead, New South Wales, Australia

${ }^{5}$ Royal Prince Alfred Hospital, Camperdown, New South Wales, Australia

${ }^{6}$ Epilepsy Action Australia, North Ryde, New South Wales, Australia

${ }^{7}$ Epilepsy Foundation, Melbourne, Victoria, Australia

${ }^{8}$ Melbourne School of Psychological Science, The University of Melbourne, Melbourne, Victoria, Australia

${ }^{9}$ Epilepsy Australia, Melbourne, Victoria, Australia

${ }^{10}$ Epilepsy Tasmania, Launceston, Tasmania, Australia

${ }^{11}$ Department of Psychological Medicine and Clinical Neurosciences, Cardiff University, Cardiff, UK

${ }^{12}$ MQ Health General Practice, Macquarie University, North Ryde, New South Wales, Australia

\section{Acknowledgements The authors would like to acknowledge the input of} Stephanie Kain with stage 2 of this study.

Contributors FR conceived the study idea, with the support of KH and TR, and wrote the first paper draft. $\mathrm{KH}$ and TR gave input into all writing and TR assisted with formatting and preparation for submission. JB supported study development and design, and reviewed first and subsequent drafts. GKH, AN, AB, CW and MK assisted with clinical epilepsy expertise and guided clinical aspects of study development as well as responding to first and subsequent drafts. CI, LT, HC, WG, $\mathrm{MB}$ and GS assisted with study design in particular aspects relating to support organisations, and responded to first and subsequent drafts. Cl, LT and MB supported the design and development of stage 2 and other aspects of nurse involvement. SV assisted with primary care design decisions and responded to first and subsequent drafts.

Funding This work is supported by Royal North Shore Hospital Neurology, Sydney; Westmead Hospital Neurology, Sydney and Royal Prince Alfred Hospital Neurology, Sydney.

\section{Competing interests None declared.}

Patient and public involvement Patients and/or the public were involved in the design, or conduct, or reporting, or dissemination plans of this research. Refer to the Methods section for further details.

Patient consent for publication Not required.

Provenance and peer review Not commissioned; externally peer reviewed.

Open access This is an open access article distributed in accordance with the Creative Commons Attribution Non Commercial (CC BY-NC 4.0) license, which permits others to distribute, remix, adapt, build upon this work non-commercially, and license their derivative works on different terms, provided the original work is properly cited, appropriate credit is given, any changes made indicated, and the use is non-commercial. See: http://creativecommons.org/licenses/by-nc/4.0/.

\section{ORCID iDs}

Frances Rapport http://orcid.org/0000-0002-4428-2826

Jeffrey Braithwaite http://orcid.org/0000-0003-0296-4957

\section{REFERENCES}

1 Lystad RP, Rapport F, Bleasel A, et al. Hospital service utilization trajectories of individuals living with epilepsy in New South Wales, Australia, 2012-2016: a population-based study. Epilepsy Behav 2020;105:106941.

2 Deloitte Access Economics. The economic burden of epilepsy in Australia. Sydney, Australia: Epilepsy Australia, 2020. https://www2. deloitte.com/au/en/pages/economics/articles/economic-burden-ofepilepsy-australia.html

3 Kwan P, Schachter SC, Brodie MJ. Drug-Resistant epilepsy. N Engl J Med Overseas Ed 2011;365:919-26.

4 Jobst BC, Cascino GD. Resective epilepsy surgery for drug-resistant focal epilepsy: a review. JAMA 2015;313:285-93.

5 Englot DJ, Chang EF. Rates and predictors of seizure freedom in resective epilepsy surgery: an update. Neurosurg Rev 2014;37:389-405.

6 Engel J. Update on surgical treatment of the epilepsies. summary of the second International palm desert conference on the surgical treatment of the epilepsies (1992). Neurology 1993;43:1612-12.

7 Fiest KM, Sajobi TT, Wiebe S. Epilepsy surgery and meaningful improvements in quality of life: results from a randomized controlled trial. Epilepsia 2014;55:886-92.

8 Mumford V, Rapport F, Shih P, et al. Promoting faster pathways to surgery: a clinical audit of patients with refractory epilepsy. BMC Neurol 2019;19:29.

9 Hutchinson K, Herkes G, Shih P, et al. Identification and referral of patients with refractory epilepsy from the primary to the tertiary care interface in New South Wales, Australia. Epilepsy Behav 2020;111:107232.

10 Rapport F, Shih P, Mitchell R, et al. Better evidence for earlier assessment and surgical intervention for refractory epilepsy (the best study): a mixed methods study protocol. BMJ Open 2017;7:e017148.

11 Engel J. Surgical treatment for epilepsy: too little, too late? JAMA 2008;300:2548-50.

12 Shih P, Nikpour A, Bleasel A, et al. Leading up to saying 'yes': A qualitative study on the experience of patients with refractory epilepsy regarding presurgical investigation for resective surgery. Epilepsy Behav 2018;83:36-43.

13 Rapport F, Shih P, Faris M, et al. Determinants of health and wellbeing in refractory epilepsy and surgery: the patient reported, implementation sciEnce (PRIME) model. Epilepsy Behav 2019;92:79-89.

14 Mitchell RJ, Herkes G, Nikpour A, et al. Examining health service utilization, hospital treatment cost, and mortality of individuals with epilepsy and status epilepticus in New South Wales, Australia 20122016. Epilepsy Behav 2018;79:9-16.

15 Rapport F, Clay-Williams R, Churruca K, et al. The struggle of translating science into action: foundational concepts of implementation science. J Eval Clin Pract 2018;24:117-26.

16 Halcomb E, Ashley C. Are Australian general practice nurses underutilised?: an examination of current roles and task satisfaction. Collegian 2019;26:522-7.

17 Barraclough F, Longman J, Barclay L. Integration in a nurse practitioner-led mental health service in rural Australia. Austr Nurs Midwif J 2016;24:144-50.

18 Booth K. Primary healthcare nursing: where great nurses go to do more. Austr Nurs Midwif J 2020;26:46.

19 Campbell F, Sworn K, Booth A, et al. Epilepsy specialist nurses the evidence (ESPENTE): a systematic mapping review 2019.

20 Prevos-Morgant M, Leavy Y, Chartrand D, et al. Benefits of the epilepsy specialist nurses (ESN) role, standardized practices and education around the world. Rev Neurol 2019;175:189-93.

21 Fitzsimons M, Normand C, Varley J, et al. Evidence-based models of care for people with epilepsy. Epilepsy Behav 2012;23:1-6.

22 Higgins A, Downes C, Varley J, et al. Rising to the challenge: epilepsy specialist nurses as leaders of service improvements and change (SENsE study). Seizure 2018;63:40-7.

23 Neurosciences \& the Senses Health Network (WA), Neurosciences $\&$ the Senses Health Network. Epilepsy review Committee, Western 
Australia. dept. of health. health networks branch. WA epilepsy services model of care. Subiaco, WA: Health Networks Branch, 2008.

24 National Institute of Clinical Excellence (NICE). Epilepsy in adults quality statement 5: epilepsy specialist nurse. NICE clinical guideline 137 recommendation 1.8.3.

25 Higgins A, Murphy R, Downes C, et al. Factors influencing the implementation of epilepsy specialist nurse role: using the consolidation framework for implementation research. $J$ Clin Nurs 2020;29:1352-64.

26 Higgins A, Downes C, Varley J, et al. Patients with epilepsy care experiences: comparison between services with and without an epilepsy specialist nurse. Epilepsy Behav 2018;85:85-94.

27 Dunne EG, Kettler LJ. Grandparents raising grandchildren in Australia: exploring psychological health and grandparents' experience of providing kinship care. Int J Soc Welf 2008;17:333-45.
28 Creswell JW, Clark VLP. Designing and conducting mixed methods research. Sage publications, 2017.

29 Braun V, Clarke V. Using thematic analysis in psychology. Qual Res Psychol 2006;3:77-101.

30 Holcomb ZC. Fundamentals of descriptive statistics. Routledge, 2016.

31 Valentine K, Jenkins B, Brennan D, CASS B. information provision to Grandparent kinship carers: responding to their unique needs. Australian Social Work 2013;66:425-39.

32 QSR International. NVivo Qualitative Data Analysis Software 1999 [Ver 12. Available: https://qsrinternational.com/nvivo/nvivoproducts

33 Fereday J, Muir-Cochrane E. Demonstrating rigor using thematic analysis: a hybrid approach of inductive and deductive coding and theme development. Int J Qual Methods 2006;5:80-92. 